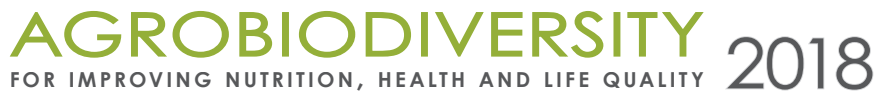

(3) -

\section{A COMPARATIVE STUDY OF EFFECT OF VARIOUS SANSEVIERIA THUNB. LEAF EXTRACTS ON THE LIPID PEROXIDATION IN THE EQUINE ERYTHROCYTE SUSPENSION}

\author{
Tkachenko Halyna*1, Buyun Lyudmyla ${ }^{2}$, \\ Maryniuk Myroslava ${ }^{2}$, Osadowski Zbigniew ${ }^{1}$ \\ ${ }^{1}$ Institute of Biology and Environmental Protection, Pomeranian University in Słupsk, Poland \\ ${ }^{2}$ M.M. Gryshko National Botanic Garden, National Academy of Science of Ukraine, Kyiv, Ukraine
}

Received: 29. 10. 2018 Revised: 30. 10.2018 Published: 10. 12. 2018

In this study, we continued our investigations concerning the interaction of leaf extracts obtained from various Sansevieria species with the equine erythrocytes. The purpose of the present study was to compare the in vitro effect of buffer extracts obtained from leaves of various species from Sansevieria genus against lipid peroxidation in equine erythrocytes. The succulent leaves of living Sansevieria plants were sampled for the study. The results of the study showed that the leaves of $S$. francisii and S. forskaliana led to a non-significantly decrease of 2-thiobarbituric acid reactive substances (TBARS) concentration in erythrocytes. However, S. hyacinthoides and S. cylindrica had a significant increase of TBARS level in the extract-treated erythrocytes (by 29.7 and $21 \%, p<0.05$, respectively). The outcome of this study suggests that Sansevieria species has a promising antioxidant and prooxidant potential. Further studies involving bioassay-guided identification of the main compounds in plants is necessary to affirm and maximize the possible use of the plant as a therapeutic remedy for prevention of lipid peroxidation in erythrocytes. The antioxidative and prooxidative mechanism of various Sansevieria species in equine erythrocyte suspension will be further studied in detail. The obtained information may be useful in the clinical usage of plants in medicine and veterinary.

Keywords: Sansevieria Thunb., extracts, 2-thiobarbituric acid reactive substances (TBARS), equine erythrocytes

\section{Introduction}

Recently, tropical and subtropical plants containing antioxidants have become an area of scientific research because they have greater health benefits with various pharmacological activities. Sansevieria Thunb., a genus with diverse ethnobotanical uses in its geographical distribution range, has occupied an important place among plant genera applied for treatment of a broad spectrum of diseases and disorders (Khalumba et al., 2005; Staples and Herbst, 2005;

*Corresponding author: Halyna Tkachenko, Institute of Biology and Environmental Protection, Pomeranian University in Słupsk, Arciszewski Str. 22b, 76-200 Słupsk, Poland; $\triangle$ tkachenko@apsl.edu.pl 
Takawira-Nyenya et al., 2014). The use of these plants in folk medicinal remedies for treating various health problems has been reported. These plants have been tested in the treatment of hemorrhoids, pain, smallpox, chicken-pox, and measles, venereal diseases, malnutrition, paralysis, epilepsy, convulsions, and spasm, pulmonary troubles, and a vermifuge, as well as a remedy for parasitic infections. In studies carried out in Nakuru and Maragua districts of Kenya by Khalumba et al. (2005), they identified five use categories of Sansevieria plants, namely medicine $(33 \%$ of the reports), fibers $(24 \%)$, soil conservation $(22 \%)$, fodder $(18 \%)$, and other uses (14\%) for four species, Sansevieria ehrenbergii Schweinf. ex Baker,S. parva N.E.Br., S. raffillii N.E. Br., and S. suffruticosa N.E. Br. Chhabra et al. (1987) mentioned the use of $S$. bagamoyensis N.E.Br. for the treatment of convulsive fever in Tanzania. Watt and BreyerBrandwijk (1962) listed the use of S. hyacinthoides (L.) Druce in the treatment of a toothache and earache and the use of the rhizome decoction of $S$. kirkii as a purgative both reported from East Africa. Yet, Kiringe (2006) reported on the use of S. volkensii Gürke for the treatment of sexually transmitted diseases such as gonorrhea. In Kenya, Owuor and Kisangau (2006) included the use of $S$. parva leaf sap for treatment of snake bite wounds and S. kirkii Baker extracts for treatment of snake bite wounds. The ethanol and water extracts of $S$. trifasciata Prain leaves showed a dose-dependent and significant increase in pain threshold and possess mild analgesic properties (Anbu et al., 2009). This seems to provide a rationale for the use of this plant in fever and inflammatory disorders. In Africa, the plant is used as a protective charm against evil or bewitchment (Stafford et al., 2008). The use of the plant in folk medicine for the treatment of different ailments such as ear-ache, ulcer, jaundice, pharyngitis, skin itches, urinary diseases, analgesic and antipyretic is well known (Ighodaro et al., 2017). Moreover, the aqueous root extract of S. liberica Gerome and Labroy is used in African folklore medicine for ailments including chronic pain, inflammatory conditions, and convulsive disorders (Amida et al., 2007). The root part of S. liberica is used in ethnomedicine in the treatment of fever, headache and cold, as well as analgesic, antibiotic and anti-inflammatory (Watt and Breyer-Brandwijk, 1962). Preparations of the S. liberica are commonly used across Nigeria for the treatment of inflammatory conditions (Akindele et al., 2015). Nevertheless, in spite of these data, Takawira-Nyenya et al. (2014) reported that the documentation of ethnobotanical uses of genus Sansevieria is incomplete.

Hence, it has been demonstrated that Sansevieria spp. plant biomaterial is a superior biosorbent for trimethylamine (TMA) removal. Both living and non-living Sansevieria spp. can be effectively used for removal of trimethylamine (TMA). Boraphech et al. (2016) have studied cleanup of trimethylamine (fishy odor) from the contaminated air by various species of Sansevieria spp. and their leaf materials. The results showed that living S. kirkii plant was the most effective while $S$. masoniana was the least effective in TMA removal. Two major pathways were involved in stomata opening and epicuticular wax on the leaf surface. In the presence of TMA, the stomata opening in Sansevieria spp. was induced, which enhanced TMA removal under light conditions (Boraphech et al., 2016). Boraphech and Thiravetyan (2015) have investigated the possible mechanisms of trimethylamine (TMA) degradation and mineralization by highly efficient C3 and crassulacean acid metabolism (CAM) plants. From screening 23 plant species, Pterocarpus indicus (C3) and S. trifasciata (CAM metabolism) were the most effective in polar gaseous trimethylamine uptake, reaching up to $90 \%$ uptake of initial 
TMA (100 ppm) within $8 \mathrm{~h}$, and could remove TMA at cycles 1-4 without affecting photosystem II (PSII) photochemistry. Up to 55 and $45 \%$ of TMA was taken up by S. trifasciata stomata and leaf epicuticular wax, respectively. During cycles 1-4, interestingly, S. trifasciata changed its stomata apertures, which was directly induced by gaseous TMA and light treatments. Fatty acids, particularly tetradecanoic (C14) acid and octadecanoic (C18) acid, were found to be the main cuticular wax components in both plants and were associated with TMA removal ability. Moreover, the plants could degrade TMA via multiple metabolic pathways associated with carbon/nitrogen interactions (Boraphech and Thiravetyan, 2015).

In our previous study (Buyun et al., 2016; Tkachenko et al., 2017), we have evaluated the antibacterial capacity of ten species of Sansevieria genus against Staphylococcus aureus and Escherichia coli in order to validate scientifically the inhibitory activity for microbial growth attributed by their popular use and to propose new sources of antimicrobial agents (Buyun et al., 2016; Tkachenko et al., 2017). Although antimicrobial activities of extracts obtained from leaves of various species of Sansevieria genus were investigated (Buyun et al., 2016, 2017; Tkachenko et al., 2016, 2017), no previous works have demonstrated their protective effects against lipid peroxidation. Therefore, the aim of this study was to evaluate the in vitro effect of buffer extracts obtained from the leaves of various species from Sansevieria genus against lipid peroxidation in equine erythrocytes. Erythrocytes are the most common type of blood cells and are the vertebrate body's principal means of delivering oxygen from the lungs or gills to body tissues via the blood (Pandey, Rizvi, 2010). Red blood cell along with its membrane has always been an important medium for the study due to the important role it plays in varied physiological and metabolic processes (Jha et al., 2009; Karabulut et al., 2009; Pandey et al., 2009).

Erythrocytes are especially vulnerable since they have no membrane repair and regenerative capacity (Webster and Toothill, 1987) and red cell damages by free radicals would probably be associated with hemolysis (Szweda-Lewandowska et al., 2003).

The erythrocytes of mammals represent a good model to evaluate the cytotoxicity of molecules, organic and inorganic, natural or synthetic, by cellular damage measure (Pagano and Faggio, 2015). The erythrocyte could be isolated and handled easily so that they could provide a good model for many assays (Alagawany et al., 2016; Farag and Alagawany, 2018). Additionally, the high concentration of polyunsaturated fatty acids in RBCs membrane, the high oxygen tension, and redox active hemoglobin molecules [the source of reactive oxygen species in erythrocyte] make them a good biological lipid membrane model especially for screening the oxidative stress conditions induced by various substances (Farag and Alagawany, 2018).

Our present study is in agreement with results obtained in our previous study including assessment of antioxidant activity of extracts obtained from leaves of selected species from Sansevieria species (Tkachenko et al., 2017). When erythrocytes were incubated with leaf extracts of various species from Sansevieria genus, the aldehydic derivatives level was significantly reduced by $13.6 \%(p<0.05)$ for S. forskaliana extract. Moreover, all extracts (except $S$. francisii extract) reduced the formation of intracellular aldehydic derivatives of oxidatively modified proteins (OMP) in the extracts-treated erythrocytes, but these results were nonsignificant. Treatment by extracts of various Sansevieria species reduced the concentration of 
ketonic derivatives of OMP when compared to untreated erythrocytes. The most potent effect was demonstrated by the S. canaliculata, S. forskaliana, S. aethiopica, S. cylindrica, S. metallica, $S$. hyacinthoides, and $S$. kirkii compared to control samples (phosphate buffer) $(16.1,14.7$, $13.4,12.9,12.9,12.7,12.1 \%$, respectively). However, there were no significant changes in other extracts. The experimental evidence obtained in our previous study indicated that various species of Sansevieria genus are a rich source of compounds that manifest antioxidant activity and can effectively protect erythrocytes against oxidative-induced damage. Thus, S. canaliculata, S. forskaliana, S. aethiopica, S. cylindrica, S. metallica, S. hyacinthoides, and S. kirkii may be a valuable source of natural antioxidants that may potentially be recommended for applications in medicine and veterinary practice. According to the above-mentioned antioxidant mechanisms, extracts of various species from Sansevieria genus may inhibit the formation of protein carbonyl by scavenging free radicals formed in vitro. According to many supporting documents, it can be assumed that secondary plant metabolites, i.e. polyphenolic compounds in extracts of various species from Sansevieria genus extract may contribute to the antioxidant activity (Tkachenko et al., 2017).

The main purpose of our present study was to evaluate the level of 2-thiobarbituric acid reactive substances (TBARS) as biomarkers of lipid peroxidation in equine erythrocyte suspension induced by treatment of leaf extracts obtained from various species of Sansevieria genus.

\section{Materiall and methodology}

\section{Collection of plant material}

The leaves of Sansevieria plants, cultivated under glasshouse conditions, were sampled at M.M. Gryshko National Botanic Garden (NBG), National Academy of Science of Ukraine. Specifically, the leaves of Sansevieria francisii Chahin, S. caulescens N.E.Br., S. suffruticosa N.E.Br., S. roxburghiana Schult. \& Schult.f., S. metallica Gérôme \& Labroy, S. gracilis N.E.Br., S. hyacinthoides (L.) Druce, S. cylindrica Bojer ex Hook., S. canaliculata Carrière, S. aethiopica Thunb., S. kirkii Baker, S. trifasciata Prain, S. forskaliana (Schult. \& Schult.f.) Hepper \& J.R.I.Wood, S. fischeri (Baker) Marais, S. dooneri N.E.Br., S. intermedia N.E.Br., S. parva N.E.Br. were sampled for the study. Various databases available for searching collections of living plants, e.g. World Checklist of Selected Plant Families (WCSP, 2018), International Plant Names Index, The Plant List, have been used for the taxonomic identity of plants screened.

\section{Preparation of plant extracts}

Freshly collected leaves were washed, weighted, crushed, and homogenized in $0.1 \mathrm{M}$ phosphate buffer (pH 7.4) (in proportion $1: 19$, w/w) at room temperature. The extracts were then filtered and investigated for their antioxidant activity. All extracts were stored at $-20{ }^{\circ} \mathrm{C}$ until use.

\section{Horses}

Eighteen healthy adult horses from central Pomeranian region in Poland (village

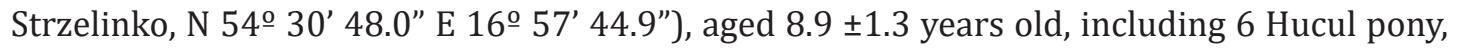


5 Thoroughbred horses, 2 Anglo-Arabian horses and 5 horses of unknown breed, were used in this study. All horses participated in recreational horseback riding. Horses were housed in individual boxes, with feeding (hay and oat) provided twice a day, at 08.00 and $18.00 \mathrm{~h}$, and water available ad libitum. All horses were thoroughly examined clinically and screened for hematological, biochemical and vital parameters, which were within reference ranges. The females were non-pregnant.

\section{Collection of blood samples}

Blood samples were taken simultaneously in all horses from the jugular vein in the morning, 90 minutes after feeding, while the horses were in the stables (between 8:30 and $10 \mathrm{AM}$ ). Whole blood was stored in sterile tubes with sodium citrate as the anticoagulant and held on the ice until centrifugation at $3000 \mathrm{rpm}$ for $5 \mathrm{~min}$ at $4{ }^{\circ} \mathrm{C}$ using a refrigerated centrifuge to remove plasma. The separated erythrocytes were washed three times in $4 \mathrm{mM}$ phosphate buffer saline (PBS), pH 7.4. After centrifugation, the supernatant and the buffy coat were carefully removed with each wash. Washed erythrocytes were finally re-suspended to the desired hematocrit level in $4 \mathrm{mM}$ PBS. The erythrocytes were stored at $4{ }^{\circ} \mathrm{C}$ and used within $2 \mathrm{~h}$ of sample preparation. A volume of $0.1 \mathrm{~mL}$ of the various extracts was added to $1.9 \mathrm{~mL}$ of clean equine erythrocyte suspension. For positive control, PBS was used. After incubation the mixture at $37^{\circ} \mathrm{C}$ for $60 \mathrm{~min}$ with continuous stirring, it was centrifuged at $3000 \mathrm{rpm}$ for $5 \mathrm{~min}$. Erythrocytes aliquots were used in the study.

\section{Quantitative estimation of lipid peroxidation by determination of the 2-thiobarbituric acid reactive substances (TBARS)}

The most important product of lipid peroxidation reacting with thiobarbituric acid (TBA) is malondialdehyde (MDA) (Lykkesfeldt, 2007). Therefore, the lipid peroxidation was determined by quantifying the concentration of TBARS by Kamyshnikov (2004) for determining the malonic dialdehyde (MDA) concentration. Briefly, $0.1 \mathrm{~mL}$ of erythrocyte suspension was added to $1 \mathrm{~mL}$ of $20 \%$ of trichloroacetic acid (TCA) and $1 \mathrm{~mL}$ of $0.8 \%$ of 2 -thiobarbituric acid (TBA). The mixture was heated in a boiling water bath for $10 \mathrm{~min}$. After cooling, the mixture was centrifuged at $3000 \mathrm{~g}$ for $10 \mathrm{~min}$. The absorbance of the supernatant was measured at $540 \mathrm{~nm}$. The concentration of MDA ( $\mu \mathrm{mol}$ per $\mathrm{mL}$ ) was calculated using $1.5610^{5} \mathrm{mM}^{-1} \mathrm{~cm}^{-1}$ as the extinction coefficient.

\section{Statistical analysis}

The mean \pm the standard error of the mean (S.E.M.) values were calculated for each group to determine the significance of the intergroup difference. All variables were tested for normal distribution using the Kolmogorov-Smirnov and Lilliefors test $(p>0.05)$. In order to find significant differences (significance level, $p<0.05$ ) between groups, the Kruskal-Wallis test by ranks was applied to the data (Zar, 1999). All statistical analyses were performed using Statistica 8.0 software (StatSoft, Krakow, Poland). 


\section{Results and discussion}

Figure 1 illustrates the level of 2-thiobarbituric acid reactive substances (TBARS) in equine erythrocyte suspension induced by treatment of leaf extracts obtained from various species of Sansevieria genus as compared with treatment by phosphate buffer (control).

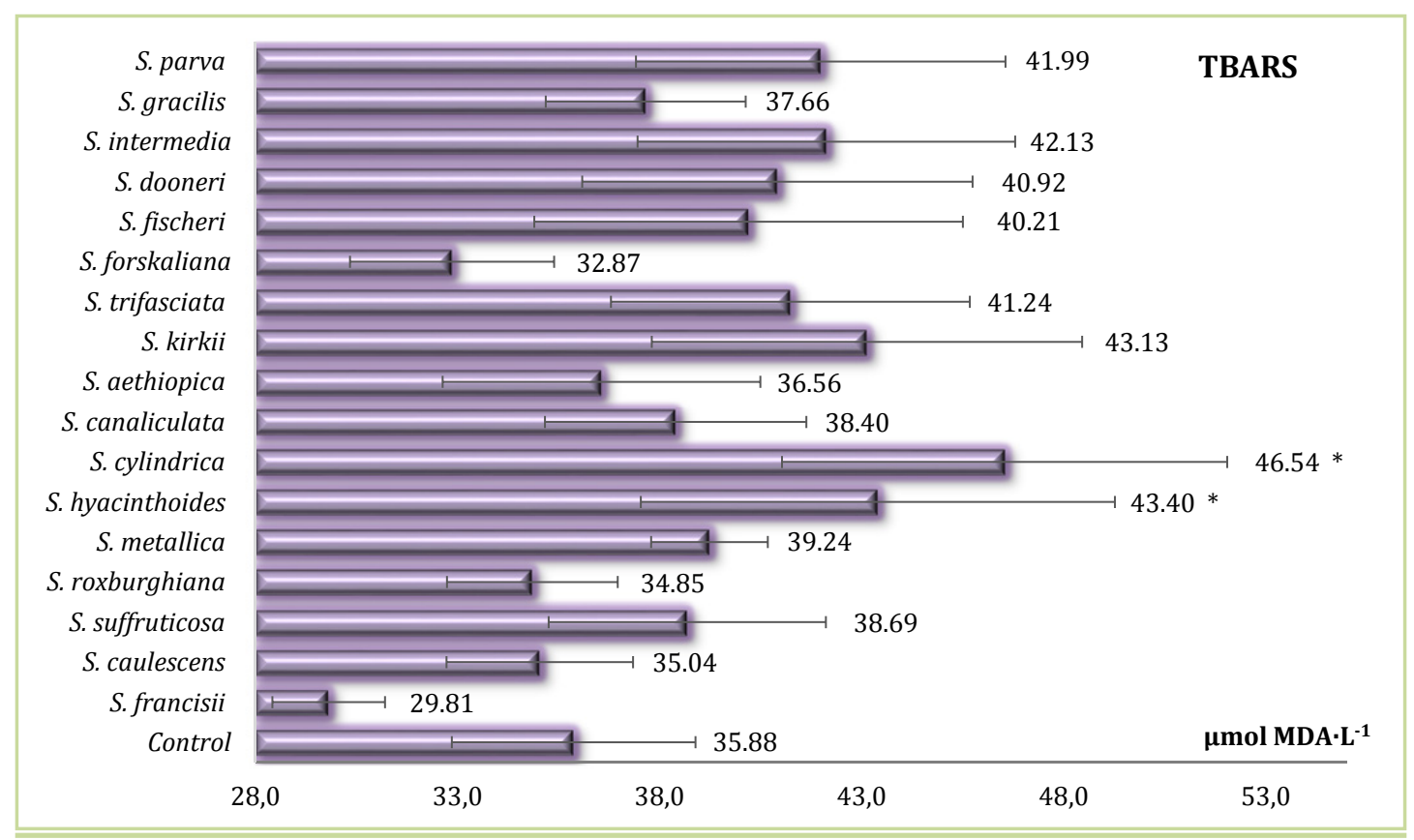

Figure 1 The level of 2-thiobarbituric acid reactive substances (TBARS) in equine erythrocyte suspension induced by treatment of leaf extracts obtained from various species of Sansevieria genus as compared with treatment by phosphate buffer (control). The data were presented as The mean \pm the standard error of the mean (S.E.M.) and analyzed using one-way analysis on ranks (ANOVA) using Kruskal-Wallis test by ranks

$* P$ value $<0.05$ was considered as significant $(n=18)$

According to the results from the protective effect of extracts obtained from leaves of selected Sansevieria species, the incubation time of $1 \mathrm{~h}$ was chosen for assessing the concentration of TBARS in erythrocyte suspension. At $1 \mathrm{~h}$ of incubation, the TBARS concentration of untreated erythrocytes was $35.88 \pm 3.02 \mu \mathrm{mol} / \mathrm{L}$. The results indicated that extracts of $S$. francisii and S. forskaliana led to a decrease of TBARS concentration in erythrocytes (by 16.9 and $8.4 \%$, $p>0.05$, respectively). These changes were statistically non-significant $(p>0.05)$. When erythrocytes were incubated with $S$. aethiopica, S. caulescens, S. roxburghiana, S. gracilis, the TBARS level was similar to that of the untreated erythrocytes. In the meantime, the treatment of S. canaliculata, S. suffruticosa, S. metallica, S. fischeri, S. dooneri, S. trifasciata, S. parva, S. intermedia, and $S$. kirkii non-significantly increase the formation of intracellular TBARS in the extract-treated erythrocytes by approximately $7-20 \%$, respectively. However, S. hyacinthoides and S. cylindrica had a significant increase of TBARS level in the extract-treated erythrocytes (by 29.7 and $21 \%, p<0.05$, respectively) (Figure 1 ). 
In this study, $S$. hyacinthoides and S. cylindrica caused a significant increase of TBARS level in the extract-treated erythrocytes (Figure 1). Despite the medicinal relevance of plants, our studies have suggested that these plants are potentially pro-oxidant in dose studied (50 mg per $\mathrm{mL}$ ). The chemical compounds responsible for the toxic effects of plants are probably produced as part of the plant's defence mechanism against pest and herbivores or to gain an advantage over competing for plants (Ighodaro et al., 2017). According to the results obtained, we addressed the hypothesis that by-products in the extracts of various Sansevieria species can be responsible for their prooxidant activity. Phytochemical screening of the plants has shown the presence of carbohydrates, saponins, glycosides, flavonoids, steroids in the leaves (Mimaki et al., 1996, 1997). The interest in possible health benefits of flavonoids has increased owing to their potent antioxidant and free radical scavenging activities observed in vitro. Nevertheless, the antioxidant efficacy of flavonoids in vivo is less documented and their prooxidant properties have been actually described in vivo (Procházková et al., 2011). Studies evidently indicate that natural antioxidants, including polyphenols, flavonoids, anthocyanins, and carotenoids, can act as pro-oxidants, which produce reactive oxygen species and cause oxidative stress (Eghbaliferiz and Iranshahi, 2016). Due to their prooxidant properties, they are able to cause oxidative damage by reacting with various biomolecules, such as lipids, proteins, and DNA (Procházková et al., 2011). The prooxidant activity is typically catalyzed by metals, particularly transition metals such as $\mathrm{Fe}$ and $\mathrm{Cu}$, present in biological systems (Eghbaliferiz and Iranshahi, 2016).

In our previous study we have evaluated the lipid peroxidation biomarkers and total antioxidant capacity in the muscle tissue of rainbow trout (Oncorhynchus mykiss Walbaum) under incubation with extracts derived from the leaves of various Sansevieria species, aimed at the further improving methods for preventing and treating fish diseases by increasing the natural resistance of fish organism using antibacterial and antioxidant agents in aquaculture (Maryniuk et al., 2017). The most potent antioxidant effect was demonstrated for the extracts of S. caulescens, S. suffruticosa, S. hyacinthoides, S. canaliculata, S. aethiopica, S. gracilis, and S. parva as compared to phosphate buffer control $(46.6,66.8,77.3,49.8,71.1,63.4,39.4 \%$, respectively). The results showed that extracts of $S$. hyacinthoides and $S$. aethiopica efficiently increased the total antioxidant capacity in rainbow trout muscle tissue (Maryniuk et al., 2017). Among plant extracts screened for in vitro antioxidant properties in rainbow trout muscle tissue, the strongest toxicity responses were exhibited by S. cylindrica, S. canaliculata, S. trifasciata, S. metallica extracts (Maryniuk et al., 2017).

On the other hand, many studies clearly demonstrate that various plants of Sansevieria genus are effective agents in the treatment and prevention of many diseases and disorders. For instance, the results obtained in a study of Adeyemi et al. (2009) suggest that the aqueous root extract of $S$. liberica possesses antidiarrhoeal property due to inhibition of gastrointestinal propulsion and fluid secretion, possibly mediated through inhibition of the nitric oxide pathway. This justifies the use of the plant extract for the treatment of diarrhea.

Moreover, Akindele et al. (2015) have evaluated the anticancer activity of root extracts of S. liberica using a combination of in vitro and in vivo models. Sulforhodamine B (SRB) in vitro cytotoxicity assay, Sarcoma-180 (S-180) ascites and solid tumor, and L1210 lymphoid leukemia 
in vivo models were used in their study. The hydroethanolic extract of the root of $S$. liberica (SL-A002) was significantly active $\left(\mathrm{IC}_{50} \leq 30 \mu \mathrm{g} \cdot \mathrm{mL}^{-1}\right.$ ) against HeLa cancer cell line (Mothana et al., 2009), the aqueous extract (SL-A003) against HCT-116, and the dichloromethane: methanol (DCM : MeOH; $70: 30$ ) extract (SL-A004) against THP-1 and A549 human cancer cell lines. Only SL-A002 showed significant activity in the Sarcoma-180 ascites model with peak tumor growth inhibition of $89.36 \%$ produced at the dose of $120 \mathrm{mg} \cdot \mathrm{kg}^{-1}$ relative to $97.96 \%$ for standard drug 5-FU at $20 \mathrm{mg} \cdot \mathrm{kg}^{-1}$. The hydroethanolic extract of $S$. liberica was subsequently found to be active in the Sarcoma-180 solid tumor model eliciting $47.40 \%$ tumor growth inhibition at the dose of $100 \mathrm{mg} \cdot \mathrm{kg}^{-1}$ compared to $50.18 \%$ for standard drug 5-FU at the dose of $20 \mathrm{mg} \cdot \mathrm{kg}^{-1}$. This extract was also found to be significantly active in the L1210 lymphoid leukemia model (Akindele et al., 2015).

Amida et al. (2007) have investigated the acute and subchronic toxicity patterns of the S. liberica. Acute toxicity tests were carried out in mice, and the median lethal dose was estimated. Subchronic (52 days) studies were conducted in rats with oral daily doses of 80,400 and $2000 \mathrm{mg} \cdot \mathrm{kg}^{-1}$. Parameters observed for at the end of chronic tests included changes in body and vital organ weights, mortality, hematological, biochemical, hepatic and male reproductive effects. S. liberica did not produce any visible toxicities or mortality with oral doses up to 20 g.kg ${ }^{-1}$ within 14 days of single treatment, but i.p. administration caused mortalities with LD50 of $668.3 \pm 47.6 \mathrm{mg} . \mathrm{kg}^{-1}$. In the chronic tests, neither mortality nor visible signs of lethality were seen in rats. No significant change in the weight of the kidney, liver, heart, and spleen, but at $400 \mathrm{mg} \cdot \mathrm{kg}^{-1}$, a significant reduction in weight of the lungs was recorded. Significant increases in the weight of testes, sperm count, and motility were produced. There were no changes in the sperm head and tail abnormalities, but significant increases in the percentage of normal sperm cells. Biochemical parameters like the aminotransferases were not affected, but a significant increase in alkaline phosphatase and uric acid levels, at 2 g.kg-1 , was detected. Significant increase and decrease in red blood cells and white blood cells were recorded, respectively, but no changes in levels of platelet volume and hemoglobin level. Results of Amida et al. (2007) indicated that the aqueous root extract of S. liberica shows that it is relatively safe when given orally, and there is a pointer toward possible usefulness to boost red blood cells and increase sperm quality, but findings indicate potential to affect hepatic cells at high doses, when administered chronically (Amida et al., 2007).

The treatment with the plant extracts of the rhizomes of $S$. liberica protects the liver against carbon tetrachloride-induced hepatotoxicity in Wistar albino rats (Ikewuchi et al., 2011). On gas chromatographic analysis of the extract, twenty nine known flavonoids were detected, consisting mainly of $31.94 \%$ apigenin, $20.66 \%$ quercetin, $11.28 \%$ kaempferol, $5.99 \%$ naringenin, 5.83\% (-)-epicatechin, 3.69\% biochanin, 3.58\% (+)-catechin, 2.72\% daidzein, $2.20 \%$ ellagic acid, $2.04 \%$ butein. The extract showed very significant hepatoprotection against carbon tetrachloride-induced hepatotoxicity in the rats, by reducing plasma total bilirubin and protein, plasma alkaline phosphatase, alanine and aspartate transaminases levels. The reduction towards the normal value, of the levels of these plasma indices of liver integrity and function, is an indication of the ability of the extract to protect normal structural and functional integrity of the poisoned liver, and also to protect against subsequent carbon 
tetrachloride hepatotoxicity, enabling regeneration process. A fact that was confirmed by histopathological studies on liver sections: that revealed that the treated animals had normal hepatic cells. This hepatoprotective activity may have been produced via inhibiting lipid peroxidation by exerting a membrane-stabilizing action or inhibiting cytochrome $\mathrm{P}_{450}$ aromatase (Ikewuchi et al., 2011).

The antioxidant and antiproliferative activities of $S$. roxburghiana methanol extract and its fractions have been explored by Maheshwari et al. (2017). Anti-proliferative effect of the extract and fractions were evaluated in HCT-116, HeLa, MCF-7, HepG2, and A-549 cancer cell lines by 3-(4,5-dimethylthiazol-2-yl)-2,5-diphenyltetrazolium bromide (MTT) and sulforhodamine B (SRB) assay methods. High-performance liquid chromatography (HPLC) and high-performance thin layer chromatography (HPTLC) fingerprint profiling were carried out for extract and different fractions. Significant antioxidant and anti-proliferate activity were detected in ethyl acetate fraction. Ethyl acetate fraction showed prominent scavenging activity in 1,1-diphenyl-2-picrylhydrazyl, 2,2'-azino-bis (3-ethylbenzothiazoline-6-sulfonic acid) diammonium salt, and nitric oxide antioxidant assays with a concentration yielding 50\% inhibition $\left(\mathrm{IC}_{50}\right)$. Cytotoxicity of ethyl acetate fraction of $S$. roxburghiana was the highest among other fractions against HCT-116, HeLa, and MCF-7cancer cell lines with IC $_{50}$ values, by MTT and by SRB assay. The presence of gallic acid in the ethyl acetate fraction of $S$. roxburghiana rhizomes was confirmed by HPLC and HPTLC analysis. Results of Maheshwari et al. (2017) suggested that the ethyl acetate fraction of $S$. roxburghiana exhibited effective antioxidant and antiproliferative activities. The phenolic compounds identified in ethyl acetate fraction could be responsible for the activities (Maheshwari et al. 2017).

In a study by Bhattacharjee et al. (2017), the therapeutic potential of protocatechuic acid isolated from the $S$. roxburghiana rhizomes against DC employing a rodent model of type 2 diabetes (T2D) was examined. T2D was induced by high-fat diet + a low-single dose of streptozotocin (35 mg.kg-1 i.p.). T2D rats exhibited significantly $(p<0.01)$ high fasting blood glucose level. Alteration in serum lipid profile $(p<0.01)$ and increased levels of lactate dehydrogenase $(p<0.01)$ and creatine kinase $(p<0.01)$ in the sera of T2D rats revealed the occurrence of hyperlipidemia and diabetic pathophysiology. A significantly $(p<0.01)$ high levels of serum C-reactive protein and pro-inflammatory mediators revealed the establishment of inflammatory occurrence in T2D rats. Besides, significantly high levels of troponins in the sera revealed the establishment of cardiac dysfunctions in T2D rats. However, protocatechuic acid (50 and 100 mg. $\mathrm{kg}^{-1}$, p.o.) treatment could significantly reverse the changes in serum biochemical parameters related to cardiac dysfunctions. Molecular mechanism studies demonstrated impairment of signalling cascade, IRS1/PI3K/Akt/AMPK/p 38/GLUT4, in glucose metabolism in the skeletal muscle of T2D rats. Significant $(p<0.01)$ activation of polyol pathway, enhanced production of AGEs, oxidative stress and up-regulation of inflammatory signalling cascades (PKC/NF- $\mathrm{KB} / \mathrm{PARP}$ ) were observed in the myocardial tissue of T2D rats. However, protocatechuic acid (50 and 100 mg.kg ${ }^{-1}$, p.o.) treatment could significantly ( $p<0.05-0.01)$ stimulate glucose metabolism in skeletal muscle, regulated glycemic and lipid status, reduced the secretion of pro-inflammatory cytokines, and restored the myocardial physiology in T2D rats near to normalcy. Histological assessments were also in agreement 
with the above findings. In silico molecular docking study again supported the interactions of protocatechuic acid with different signalling molecules, PI3K, IRS, Akt, AMPK PKC, NF- $\kappa$ B, and PARP, involved in glucose utilization and inflammatory pathophysiology. In silico ADME study predicted that protocatechuic acid would support the drug-likeness character and to be a new therapeutic agent for DC in future (Bhattacharjee et al., 2017).

\section{Conclusions}

The results of the study showed that the leaf extracts of $S$. francisii and $S$. forskaliana led to a non-significantly decrease of TBARS concentration in the equine erythrocytes. When erythrocytes were incubated with $S$. aethiopica, S. caulescens, S. roxburghiana, S. gracilis, the TBARS level was similar to that of the untreated erythrocytes. In the meantime, the treatment of S. canaliculata, S. suffruticosa, S. metallica, S. fischeri, S. dooneri, S. trifasciata, S. parva, S. intermedia, and $S$. kirkii non-significantly increase the formation of intracellular TBARS in the extract-treated erythrocytes by approximately 7-20\%, respectively. However, S. hyacinthoides and S. cylindrica had significant increased TBARS level in the extract-treated erythrocytes (by 29.7 and 21\%, $p<0.05$, respectively). It can be inferred from this study, that Sansevieria species have a promising antioxidant and prooxidant potential. Further studies involving bioassayguided identification of the main compounds in plants is necessary to affirm and maximize the possible use of the plant as a therapeutic remedy for prevention of lipid peroxidation in erythrocytes. The antioxidative and prooxidative mechanism of various Sansevieria species in equine erythrocyte suspension will be further studied in detail. The obtained information may be useful in the clinical usage of plants in medicine and veterinary. Finally, these findings justify the traditional uses of Sansevieria plants for therapeutic purposes.

\section{Acknowledgement}

This study was carried out during Scholarship Program supported by The Polish National Commission for UNESCO in the Department of Zoology, Institute of Biology and Environmental Protection, Pomeranian University in Slupsk (Poland). We thank The Polish National Commission for UNESCO for the supporting our study.

\section{References}

ADEYEMI, O.O., AKINDELE, A.J., OGUNLEYE, E.A. 2009. Evaluation of the antidiarrhoeal effect of Sanseviera liberica Gerome \& Labroy (Agavaceae) root extract. In J. Ethnopharmacol., vol. 123(3), p. 459-463. http://dx.doi.org/10.1016/j.jep.2009.03.023

AKINDELE, A.J., WANI, Z.A., SHARMA, S., MAHAJAN, G., SATTI, N.K., ADEYEMI, O.O., MONDHE, D.M., SAXENA, A.K. 2015. In Vitro and In Vivo Anticancer Activity of Root Extracts of Sansevieria liberica Gerome and Labroy (Agavaceae). In Evid. Based Complement. Alternat. Med., 2015, 560404. http:// dx.doi.org/10.1155/2015/560404

ALAGAWANY, M., FARAG, M.R., EL-KHOLY, M.S., EL-SAYED, S.A.A., DHAMA, K. 2016. Effect of resveratrol, cinnamaldehyde and their combinations on the antioxidant defense system and ATP release of rabbit erythrocytes: in vitro study. In Asian J. Anim. Sci. Vet. Adv., vol. 12, p. 1-9. http://dx.doi. org/10.3923/ajava.2017.1.9 
AMIDA, M.B., YEMITAN, O.K., ADEYEMI, O.O. 2007. Toxicological assessment of the aqueous root extract of Sanseviera liberica Gerome and Labroy (Agavaceae). In J. Ethnopharmacol., vol. 113(1), p. 171175. http://dx.doi.org/10.1016/j.jep.2007.03.033

ANBU, J.S., JAYARAJ, P., VARATHARAJAN, R., THOMAS, J., JISHA, J., MUTHAPPAN, M. 2009. Analgesic and antipyretic effects of Sansevieria trifasciata leaves. In Afr. J. Tradit. Complement. Altern. Med., vol. 6(4), p. 529-533.

BHATTACHARJEE, N., DUA, T.K., KHANRA, R., JOARDAR, S., NANDY, A., SAHA, A., DE FEO, V., DEWANJEE, S. 2017. Protocatechuic-Acid, a Phenolic from Sansevieria roxburghiana Leaves, Suppresses Diabetic Cardiomyopathy via Stimulating Glucose Metabolism, Ameliorating Oxidative Stress, and Inhibiting Inflammation. In Front. Pharmacol., vol. 8, p. 251. http://dx.doi.org/10.3389/fphar.2017.00251

BORAPHECH, P., SUKSABYE, P., KULINFRA, N., KONGSANG, W., THIRAVETYAN, P. 2016. Cleanup of trimethylamine (fishy odor) from contaminated air by various species of Sansevieria spp. and their leaf materials. In Int. J. Phytoremediation, vol. 18(10), p. 1002-1013. http://dx.doi.org/10.1080/1 5226514.2016.1183569

BORAPHECH, P., THIRAVETYAN, P. 2015. Removal of trimethylamine (fishy odor) by $\mathrm{C}_{3}$ and CAM plants. In Environ. Sci. Pollut. Res. Int., vol. 22(15), p. 11543-11557. http://dx.doi.org/10.1007/ s11356-015-4364-3

BUYUN, L., MARYNIUK, M., TKACHENKO, H., OSADOWSKI, Z. 2017. Antibacterial evaluation of an ethanolic extract from Sansevieria trifasciata Prain against Staphylococcus aureus. In Proceedings of the International Scientific and Practical Internet Conference "Problems and perspectives of modern agricultural science". Mykolayiv: Mykolaiv DDSS IZZ, p. 88.

BUYUN, L., TKACHENKO, H., OSADOWSKI, Z., MARYNIUK, M. 2016. Antibacterial activity of certain Sansevieria species against Staphylococcus aureus. In Słupskie Prace Biologiczne, vol. 13, p. 19-36.

CHHABRA, S.C., MAHUNNAH, R.L.A., MSHIU, E.N. 1987. Plants used in traditional medicine in Eastern Tanzania 1. Pteridophytes and Angiosperms (Acanthaceae to Canellaceae). In Journal of Ethnopharmacology, vol. 21(3), p. 253-277. http://dx.doi.org/10.1016/0378-8741(87)90103-6

EGHBALIFERIZ, S., IRANSHAHI, M. 2016. Prooxidant Activity of Polyphenols, Flavonoids, Anthocyanins and Carotenoids: Updated Review of Mechanisms and Catalyzing Metals. In Phytother. Res., vol. 30(9), p. 1379-1391. http://dx.doi.org/10.1002/ptr.5643

FARAG, M.R., ALAGAWANY, M. 2018. Erythrocytes as a biological model for screening of xenobiotics toxicity. In Chem. Biol. Interact., vol. 279, p. 73-83. http://dx.doi.org/10.1016/j.cbi.2017.11.007

IGHODARO, O.M., ADEOSUN, A.M., OJIKO, B.F., AKOREDE, A.T., FUYI-WILLIAMS, 0. 2017. Toxicity status and antiulcerative potential of Sansevieria trifasciata leaf extract in Wistar rats. In J. Intercult. Ethnopharmacol., vol. 6(2), p. 234-239. http://dx.doi.org/10.5455/jice.20170421103553

IKEWUCHI, J.C., IKEWUCHI, C.C., IGBOH, N.M., MARK-BALM, T. 2011. Protective effect of aqueous extract of the rhizomes of Sansevieria liberica Gérôme and Labroy on carbon tetrachloride-induced hepatotoxicity in rats. In EXCLI J., vol. 10, p. 312-321.

JHA, R., RIZVI, S.I. 2009. Age-dependent decline in erythrocyte acetylcholinesterase activity: correlation with oxidative stress. In Biomed. Pap. Med. Fac. Univ. Palacky Olomouc Czech Repub., vol. 153, p. 195-198.

KAMYSHNIKOV, V.S. 2004. A reference book on the clinic and biochemical researches and laboratory diagnostics. MEDpress-inform, Moscow.

KARABULUT, I., BALKANCI, Z.D., PEHLIVANOGLU, B., ERDEM, A., FADILLIOGLU, E. 2009. Effect of toluene on erythrocyte membrane stability under in vivo and in vitro conditions with assessment of oxidant/antioxidant status. In Toxicol. Ind. Health., vol. 25, p. 545-550. 
KHALUMBA, M.L., MBUGUA, P.K., KUNG'U, J.B. 2005. Uses and conservation of some highland species of the genus Sansevieria Thunb. in Kenya. In African Crop Science Conference Proceedings, vol. 7, p. 527-532.

KIRINGE, J.W. 2006. A survey of traditional health remedies used by the Maasai of Southern Kaijiado District, Kenya. In Ethnobotany Research and Applications, vol. 4, p. 61-73. http://dx.doi. org $/ 10125 / 238$

LYKKESFELDT, J. 2007. Malondialdehyde as biomarker of oxidative damage to lipids caused by smoking. In Clin. Chim, Acta, vol. 380, p. 50-58.

MAHESHWARI, R., SHREEDHARA, C.S., POLU, P.R., MANAGULI, R.S., XAVIER, S.K., LOBO, R., SETTY, M., MUTALIK, S. 2017. Characterization of the Phenolic Compound, Gallic Acid from Sansevieria roxburghiana Schult and Schult. f. Rhizomes and Antioxidant and Cytotoxic Activities Evaluation. In Pharmacogn. Mag., vol. 13 (3), S693-S699. DOI: 10.4103/pm.pm_497_16

MARYNIUK, M., KHARCHENKO, I., BUYUN, L., TKACHENKO, H., WITASZEK, M., PAŻONTKA-LIPIŃSKI, P., OSADOWSKI, Z. 2017. Total antioxidant capacity in the muscle tissue of the rainbow trout (Oncorhynchus mykiss Walbaum) under in vitro incubation with extracts from leaves of various species of Sansevieria Thunb. (Asparagaceae). In Scientific and Technical Bulletin of Institute of Animal Husbandry, National Academy of Agrarian Sciences of Ukraine, Kharkov, vol. 118, p. 14-21.

MARYNIUK, M., KHARCHENKO, I., TKACHENKO, H., BUYUN, L., WITASZEK, M., PAŻONTKA-LIPIŃSKI, P., OSADOWSKI, Z. 2017. In vitro study of lipid peroxidation markers in the muscle tissue of the rainbow trout (Oncorhynchus mykiss Walbaum) under incubation with extracts from leaves of various species of Sansevieria Thunb. (Asparagaceae). In Scientific Journal of DALRYBVTUZ, vol. 43(4), p. 27-34.

MIMAKI, Y., INOUE, T., KURODA, M., SASHIDA, Y. 1996. Steroidal saponins from Sansevieria trifasciata. In Phytochemistry, vol. 43(6), p. 1325-1331. http://dx.doi.org/10.1016/S0031-9422(96)00397-4

MIMAKI, Y., INOUE, T., KURODA, M., SASHIDA, Y. 1997. Pregnane glycosides from Sansevieria trifasciata. In Phytochemistry, vol. 44(1), p. 107-111. http://dx.doi.org/10.1016/S0031-9422(96)00477-3

MOTHANA, R.A., LINDEQUIST, U., GRUENERT, R., BEDNARSKI, P.J. 2009. Studies of the in vitro anticancer, antimicrobial and antioxidant potentials of selected Yemeni medicinal plants from the island Soqotra. In BMC Complement. Altern. Med., vol. 9, p. 7. http://dx.doi.org/10.1186/1472-6882-9-7

OWUOR, B.O., KISANGAU, D.P. 2006. Kenyan medicinal plants used as antivenin: A comparison of plant usage. In Journal of Ethnobiology and Ethnomedicine, vol. 2(7), p. 1-8. http://dx.doi. org/10.1186/1746-4269-2-7

PAGANO, M., FAGGIO, C. 2015. The use of erythrocyte fragility to assess xenobiotic cytotoxicity. In Cell Biochem. Funct., vol. 33(6), p. 351-355. http://dx.doi.org/10.1002/cbf.3135

PANDEY, K.B., MISHRA, N., RIZVI, S.I. 2009. Myricetin may provide protection against oxidative stress in type 2 diabetic erythrocytes. In Z. Naturforsch. C., vol. 64, p. 626-630.

PANDEY, K.B., RIZVI, S.I. 2010. Markers of oxidative stress in erythrocytes and plasma during aging in humans. In Oxid. Med. Cell Longev., vol. 3(1), p. 2-12.

PROCHÁZKOVÁ, D., BOUŠOVÁ, I., WILHELMOVÁ, N. 2011. Antioxidant and prooxidant properties of flavonoids. In Fitoterapia, vol. 82(4), p. 513-523. http://dx.doi.org/10.1016/j.fitote.2011.01.018

STAFFORD, G.I., PEDERSEN, M.E., VAN STADEN, J., JÄGER, A.K. 2008. Review of plants with CNS-effects used in traditional South African medicine against mental diseases. In J. Ethnopharmacol., vol. 119(3), p. 513-537. http://dx.doi.org/10.1016/j.jep.2008.08.010

STAPLES, G.W., HERBST, D.R. 2005. A Tropical Garden Flora: Plants cultivated in the Hawaiian Island and other tropical places. Bishop Museum Press, Honolulu, Hawaii. 
SZWEDA-LEWANDOWSKA, Z., KROKOSZ, A., GONCIARZ, M., ZAJECZKOWSKA, W., PUCHALA, M. 2003. Damage to human erythrocytes by radiation-generated HO* radicals: molecular changes in erythrocyte membranes. In Free Radic. Res., vol. 37(10), p. 1137-1143.

TAKAWIRA-NYENYA, T., NEWTON, L.E., WABUYELE, E., STEDJE, B. 2014. Ethnobotanical uses of Sansevieria Thunb. (Asparagaceae) in Coast Province of Kenya. In Ethnobotany Research and Application, vol. 12(1), p. 51-69. http://dx.doi.org/10.17348/era.12.0.051-069

TKACHENKO, H., BUYUN, L., OSADOWSKI, Z., MARYNIUK, M. 2016. Potential In Vitro Antibacterial Effects of the Leaf Extracts of Sansevieria canaliculata Carrière (Dracaenaceae) Against Staphylococcus aureus. In Topical Issues in Biology and Medicine: Proceedings of the XIV Interregional Scientific Conference, Starobelsk, p. 206-210.

TKACHENKO, H., BUYUN, L., OSADOWSKI, Z., MARYNIUK, M. 2017. The antibacterial activity of certain Sansevieria Thunb. species against Escherichia coli. In Agrobiodiversity for improving nutrition, health, and life quality, vol. 1, p. 446-453. http://dx.doi.org/10.15414/ agrobiodiversity.2017.2585-8246.446-453

TKACHENKO, H., BUYUN, L., OSADOWSKI, Z., MARYNIUK, M. 2017. The antibacterial screening of certain Sansevieria species against Escherichia coli strain. In Youth and Progress of Biology: Book of Abstracts of XIII International Scientific Conference for Students and Ph.D. Students (Lviv, 25-27 April 2017), p. 220-221.

TKACHENKO, H., BUYUN, L., PAŻONTKA-LIPIŃSKI, P., WITASZEK, M., OSADOWSKI, Z. 2017. In vitro protective effect of extracts obtained from various Sansevieria species against oxidative damage of proteins in equine erythrocytes. In Słupskie Prace Biologiczne, vol. 14, p. 247-265.

TKACHENKO, H.M., BUYUN, L.I., OSADOWSKI, Z., MARYNIUK, M.M. 2017. In vitro antibacterial activity of ethanolic extracts from leaves of various Sansevieria species against Escherichia coli. In Proceedings of XII International Pirogov scientific medical conference of students and young scientists, Federal State Budget Educational Institution of Higher Education " N.I. Pirogov Russian National Research Medical University", March 17, 2017. Moscow, p. 295.

WATT, J.M., BREYER-BRANDWIJK, M.G. 1962. The Medicinal and Poisonous Plants of Southern and Eastern Africa. E \& S Livingstone Ltd., Edinburgh, Scotland.

WEBSTER, N., TOOTHILL, C. 1987. Inorganic phosphate transport across the red blood cell membrane: the effect of exposure to hyperoxia. In Clin. Chim. Acta, vol. 167(3), p. 259-265.

World Checklist of Selected Plant Families (WCSP): Royal Botanic Garden, Kew, 2018): https://wcsp. science.kew.org/

ZAR, J.H. 1999. Biostatistical Analysis, $4^{\text {th }}$ ed., Prentice Hall Inc., New Jersey. 